\title{
Effects of synthetic kisspeptin and its analogues on cell lines of malignancies of female reproductive system
}

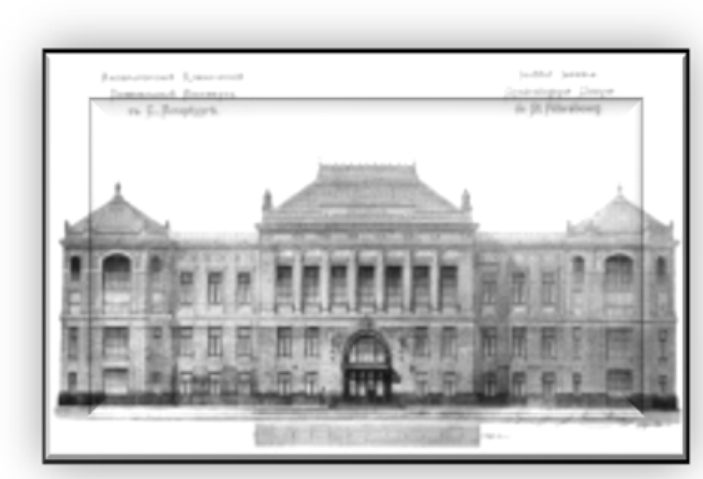

\section{Drobintseva A., Polyakova V., Kvetnoy I. Ott's research institute of obstetrics, gynecology and reproductology, Saint-Petersburg anna.drobintseva@gmail.com}

Kisspeptins are a family of protein molecules that are encoded in humans by Kiss 1 gene. Kiss 1 encodes a polypeptide comprising 145 amino acid residues (KP-145), however, the biologically active forms are KP, containing 10, 13, 14, 54 amino acid residues (Kp-10, Kp-13, Kp-14, Kp-54), they are formed by proteolytic cleavage of the molecule Kp-145. The biological activity of $\mathrm{KP}$ is determined by the presence of Arg-Phe-NH2 sequence at the $C$ - terminal region of the molecule (Fig.1).
Material and methods

Cell lines were cultured with addition of KP-10, KP-Ala and KPTrp in concentration $10^{-7} \mathrm{M}$. After 36 hours of incubation they were fixed in paraformaldehyde and analyzed by immunofluorescence technique to estimate proliferation rate (anti-Ki-67, 1:75, Dako) and level of apoptosis-associated proteins (anti-Bcl-2, 1:100, Novocastra; anti-p53 1:50, Dako, anti-caspase-3 1:400, Abcam, anti-caspase-8,-9 both 1:500, Dako).Derive samples were photographed in 5 random nonoverlapping fields of view.

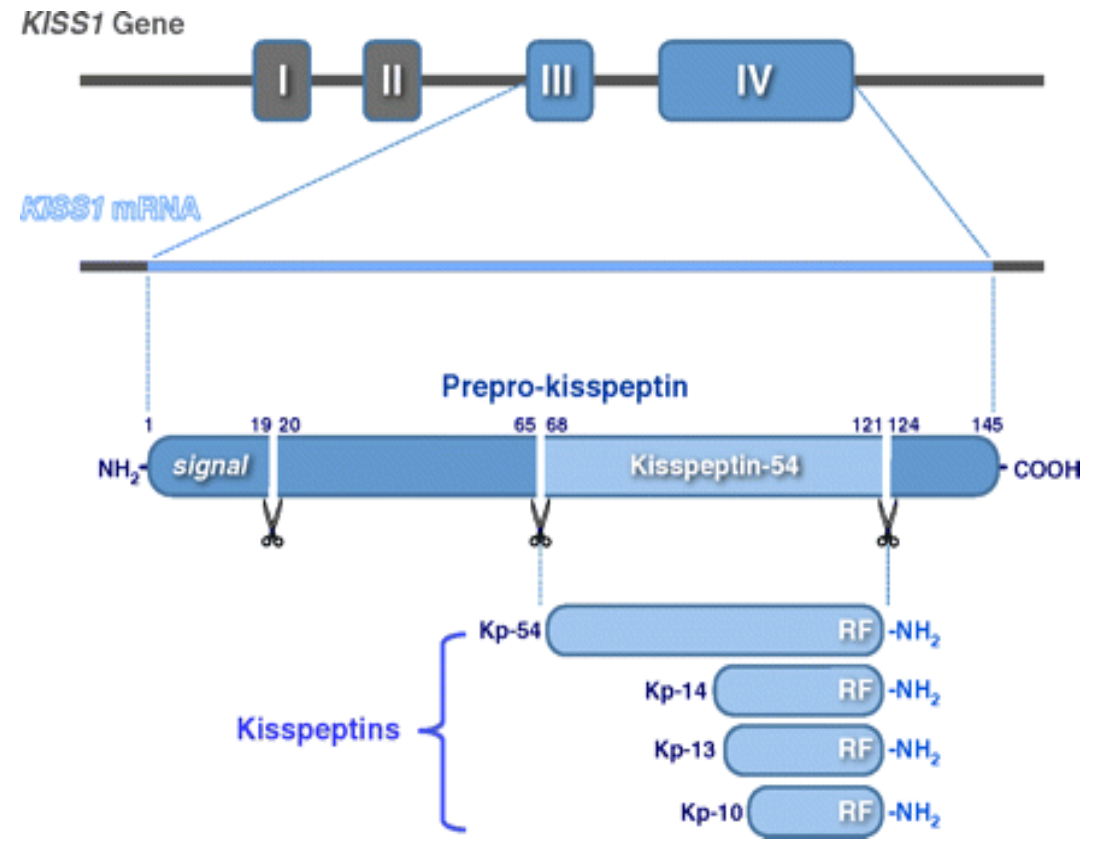

Kisspeptin functional analogs were obtained by solid phase method using Fmoc-tBu strategy.

\begin{tabular}{|c|c|c|}
\hline & Modification of kisspeptins & Puruty \\
\hline KP-10 & H-Tyr-Asn-Phe-Asn-Ser-Phe-Gly-Leu-Arg-Phe-NH & $95 \%$ \\
\hline KP-Ala & $\mathrm{H}$-Tyr-Asn-Phe-Asn-Ser-Phe-D-Ala-Leu-Arg-Phe- $\mathrm{NH}_{2}$ & $92 \%$ \\
\hline KP-Trp & H-Tyr-Asn-Phe-Asn-Ser-Phe-D-Trp-Leu-Arg-Phe- $\mathrm{NH}_{2}$ & $93 \%$ \\
\hline
\end{tabular}

The aim of the study was to identify the KP-10 and its analogues effects on proliferation and apoptosis of human breast tumor cell line (BT474 and MCF-7) and human uterine leiomyosarcoma cell line (SK-UT-1B).

Conclusion: Kisspeptin-10 and two analogues have proapototic and antiproliferative effect on tumor cell lines of female genital tract. The synthetic hormones affect cell lines in different manner it could be associated with sensitivity to estrogen, which is known for its antiapoptotic effects. KP-Trp showed the highest proapoptotic effect in cell culture.

\begin{tabular}{|c|c|c|c|c|c|c|}
\hline $\mathbf{K P}$ & Ki-67 & Bcl-2 & Caspase-8 & p53 & Caspase-9 & $\begin{array}{c}\text { Cell number, } \\
\%\end{array}$ \\
\hline \multicolumn{7}{|c|}{ Carcinoma of thoracid duct (BT-474) } \\
\hline $\begin{array}{r}\text { Contro } \\
1\end{array}$ & $83,56 \pm 10,74$ & $64,98 \pm 14,49$ & $5,80 \pm 4,27$ & $3,14 \pm 2,25$ & $0,57 \pm 0,34$ & $40,23 \pm 30,69$ \\
\hline KP-10 & $68,91 \pm 20,45$ & $54,62 \pm 19,42$ & $21,33 \pm 15,34$ & $68,91 \pm 20,45$ & $72,27 \pm 11,49$ & $33,55 \pm 29,41$ \\
\hline KP-Ala & $39,13 \pm 15,89$ & $57,75 \pm 10,88$ & $1,02 \pm 1,69$ & $43,94 \pm 23,48$ & $49,01 \pm 27,86$ & $49,40 \pm 32,10$ \\
\hline $\begin{array}{l}\text { KP- } \\
\text { Trp }\end{array}$ & $63,72 \pm 24,85$ & $8,89 \pm 14,81$ & $60,44 \pm 21,09$ & $31,56 \pm 11,71$ & $14,95 \pm 13,51$ & $25,76 \pm 19,55$ \\
\hline \multicolumn{7}{|c|}{ Uterine leyomiosarcoma (SK-UT-1B) } \\
\hline $\begin{array}{r}\text { Contro } \\
1\end{array}$ & $55,02 \pm 23,38$ & $37,63 \pm 7,07$ & $75,00 \pm 3,79$ & $34,53 \pm 4,78$ & $6,18 \pm 5,56$ & $20,12 \pm 10,87$ \\
\hline KP-10 & $47,19 \pm 27,80$ & $34,16 \pm 1,32$ & $78,88 \pm 1,24$ & $47,22 \pm 8,83$ & $60,11 \pm 4,35$ & $11,99 \pm 5,31$ \\
\hline KP-Ala & $26,50 \pm 12,02$ & $37,41 \pm 6,63$ & $56,17 \pm 16,25$ & $51,18 \pm 6,34$ & $65,34 \pm 4,25$ & $13,20 \pm 10,14$ \\
\hline $\begin{array}{l}\text { KP- } \\
\text { Trp }\end{array}$ & $44,89 \pm 27,21$ & $18,67 \pm 6,45$ & $77,89 \pm 4,27$ & $41,14 \pm 7,15$ & $67,77 \pm 1,68$ & $10,61 \pm 7,16$ \\
\hline \multicolumn{7}{|c|}{ Brest adenocarcinoma (MCF-7) } \\
\hline $\begin{array}{r}\text { Contro } \\
1\end{array}$ & $65,91 \pm 18,33$ & $7,08 \pm 1,76$ & $3,84 \pm 1,01$ & $3,39 \pm 4,64$ & $5,63 \pm 7,54$ & $23,08 \pm 15,60$ \\
\hline $\mathbf{K P}-10$ & $27,59 \pm 22,42$ & $3,64 \pm 4,77$ & $11,61 \pm 8,99$ & $34,96 \pm 13,49$ & $2,70 \pm 2,46$ & $10,62 \pm 6,68$ \\
\hline KP-Ala & $7,43 \pm 4,12$ & $6,18 \pm 1,82$ & $10,28 \pm 4,83$ & $14,98 \pm 3,54$ & $6,45 \pm 6,16$ & $14,19 \pm 23,53$ \\
\hline KP-Trp & $37,04 \pm 11,44$ & $7,12 \pm 3,25$ & $9,52 \pm 5,30$ & $9,27 \pm 5,06$ & $6,97 \pm 8,47$ & $9,93 \pm 18,65$ \\
\hline
\end{tabular}

Red - statistically significant increase $(p \leq 0.05)$

Blue- statistically significant decrease $(p \leq 0.05)$
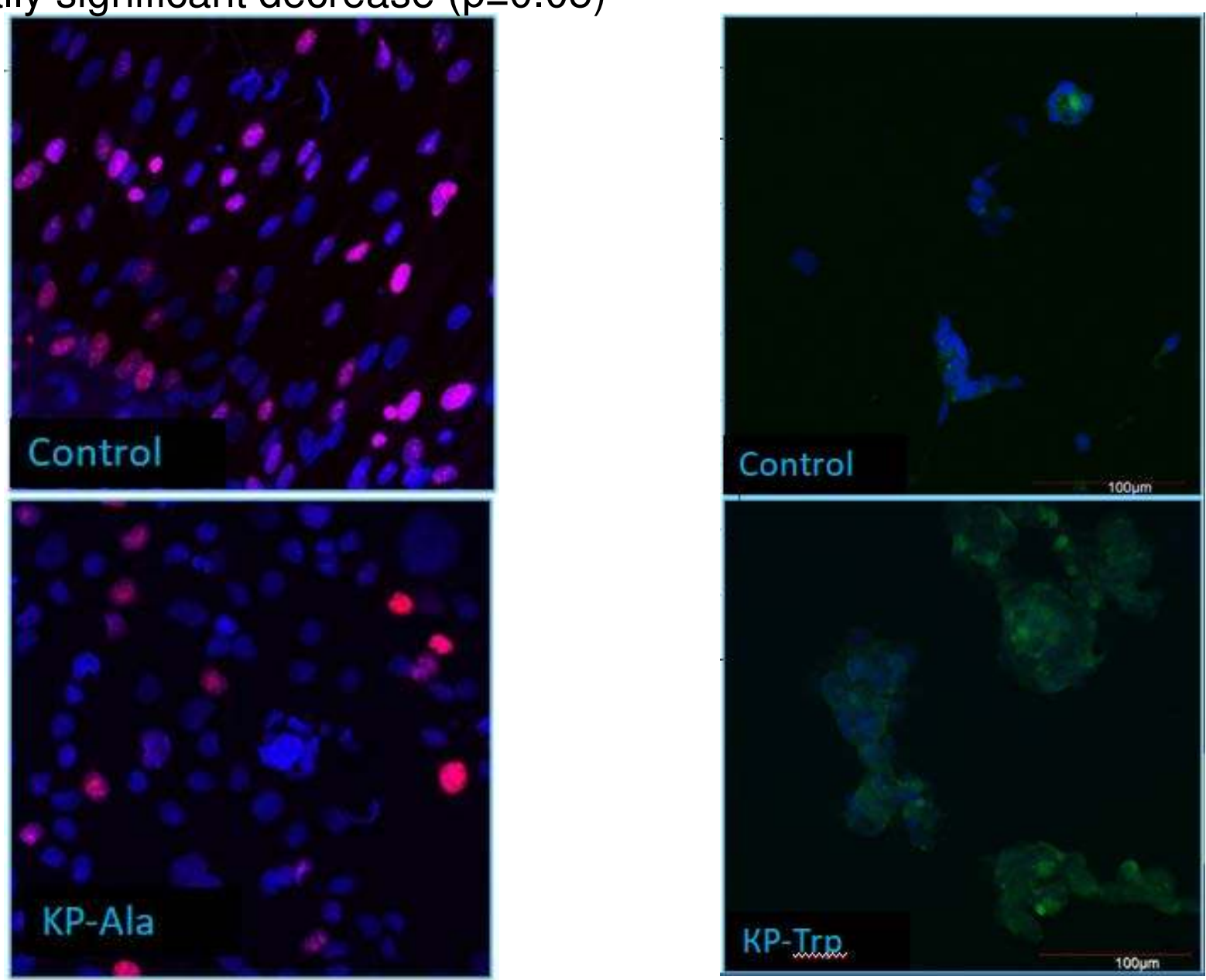